\title{
More necropsies will improve patient care: has the case been made?
}

\section{H Guly}

\section{More research is needed to show that performing necropsies will improve patient care}

W hen I attend a necropsy and discover that the patient had a disease I did not suspect, I learn something and, hopefully, am smarter next time. If the necropsy confirms my clinical diagnosis, not only is this useful in itself but to see, say, a large embolus in the pulmonary artery helps me to understand the disease process much better than any amount of imaging. Similar views are expressed in the correspondence columns of journals whenever necropsies are discussed. Receiving a necropsy report may be informative, but it is never as useful as seeing with one's own eyes. Not only do necropsies educate the individual clinician, but a high necropsy rate will help to ensure that statistics from institutions and nations are more accurate. Furthermore, as shown in the paper by Shojania et al ${ }^{1}$ published in this issue of $Q S H C$, it may significantly alter the sensitivity and specificity of established diagnostic pathways. Necropsies may be educational for medical students, but I would suggest that clinicians who get the most value from them are those who use them for self-audit as a final diagnostic test in a patient they have treated themselves.

In 1991 a Working Party of the Royal Colleges of Pathologists, Physicians and Surgeons ${ }^{2}$ in the UK recommended that necropsies should be performed to verify the cause of death based on a clinical diagnosis and in other problematic cases. They also recommended that necropsies should be undertaken in at least $10 \%$ of deaths where there was no perceived necessity for a necropsy. Among other recommendations were that necropsies should be attended by a member of the clinical team, that discrepancies between ante-mortem and post-mortem diagnoses should be monitored, and that regular mortality meetings should be held. Since then the necropsy rate has fallen further. ${ }^{3}$

It is perceived that the public dislike the idea of necropsies and this distaste has been heightened by the organ retention "scandal" in the UK. ${ }^{4}$ However, if approached correctly, most relatives will give permission for a necropsy to be performed, ${ }^{25}$ so the way to increase the necropsy rate is for more to be requested. Cameron $e^{2} a l^{6}$ increased their necropsy rate from $30 \%$ to $65 \%$ simply by instructing doctors to ask for a necropsy in every case. A more recent study by Burton et $a l^{3}$ found that the necropsy rate could be increased by delegating the task to a non-medical person.

Why are doctors requesting fewer necropsies? And why, even when a necropsy is performed, do so few clinicians attend?

One of the reasons is confidence (demonstrated as false by Shojania et $\left.a l^{1}\right)$ that modern investigations will give the correct diagnosis. Asking consent for a necropsy from a grieving relative is difficult and should not be delegated to the most junior member of the team without training. Junior doctors who have never witnessed a necropsy may find the idea of it distasteful.

There is, however, another underlying reason. I believe that only lip service is given to clinical audit, except for those few audits used by employers or monitoring organisations to judge the quality of health care-for example, surgical mortality or the door to needle time in acute myocardial infarction. A necropsy service needs proper funding to include not only the pathologist's time but also the clinician's time for seeking consent, attending the necropsy, explaining the results to relatives who want to know, and attending mortality meetings where discrepancies can be discussed with a view to changing practice.

Pressures on clinicians are increasing. With an increasing patient throughput and targets to be achieved, combined with increasing paperwork, something has to give. Similarly, the workload for pathologists is increasing and, if necropsies have to be performed without adequate funding, they are done as quickly as possible and cannot wait for the clinician to finish a ward round to attend. Pathologists can hardly be expected to be enthusiastic if the patient's clinician shows little interest.

There is a wealth of research to show that necropsies demonstrate unsuspected diagnoses including a number that might affect outcome, but what is needed is proof that this improves patient care. Can we reduce complications and lower mortality rates? Can we speed up diagnosis or improve diagnostic accuracy? Perhaps if that proof was there, reductions in negligence insurance premiums for hospitals with a necropsy rate above a certain level could be obtained and necropsies would be encouraged by governments and those who pay for health services.

It would seem self-evident that learning from one's mistakes is beneficial and will improve patient care, but there is very little evidence for this. Sonderegger-Iseli et $\mathrm{l}^{7}$ give an example of a necropsy study on patients with haematological malignancies that raised the awareness of fungal complications in the immunosuppressed patient which led to changes in clinical management and lower infection rates. Such evidence is rare and much is anecdotal.

More research is needed to show that performing necropsies will improve patient care.

Qual Saf Health Care 2005; 14:397.

doi: 10.1136/qshc.2005.016154

Correspondence to: Dr H Guly, Accident and Emergency Department, Derriford Hospital, Plymouth PL6 8DH, UK; henry.guly@phnt.swest. nhs.uk

\section{REFERENCES}

1 Shojania KG, Burton EC, McDonald KM et al. Overestimation of clinical diagnostic performance rates caused by low necropsy rates. Qual Saf Health Care 2005; 14:408-13.

2 Joint Working Party of the Royal College of Pathologists, the Royal College of Physicians of London, and the Royal College of Surgeons of England. The autopsy and audit. London: Royal College of Pathologists, 1991

3 Burton JL, Underwood JCE. Necropsy practice after the "organ retention scandal": requests, performance and tissue retention. J Clin Pathol 2003:56:537-41.

4 Bauchner H, Vinci R. What have we learned from the Alder Hey affair? BMJ 2001;322:309-10.

5 Kamal IS, Forsyth DR, Jones JR. Does it matter who requests necropsies? Prospective study of effect of clinical audit on rate of requests. $B M$ 1997:314:1729.

6 Cameron HM, McGoogan E, Watson $\mathrm{H}$. Necropsy: a yardstick for clinical diagnoses. BMJ 1980;281:985-8.

7 Sonderegger-Iseli K, Burger S, Muntwyler J, et al. Diagnostic errors in three medical eras: a necropsy study. Lancet 2000;355:2027-31 